\title{
DIVERSIDADE SEXUAL NAS ORGANIZAÇÕES: UM ESTUDO SOBRE COMING OUT
}

\author{
SEXUAL DIVERSITY IN ORGANIZATIONS: A STUDY ON COMING OUT
}

Recebido em 22.09.2013. Aprovado em 19.03.2014 Avaliado pelo sistema double blind review DOI: $\underline{\text { http://dx.doi.org/10.12712/rpca.v8i1.316 }}$

\author{
Henrique Luiz Caproni Neto \\ henriquecap_adm@yahoo.com.br \\ Universidade Federal de Minas Gerais, Belo Horizonte, MG - Brasil
}

Luiz Alex Silva Saraiva

saraiva@face.ufmg.br

Universidade Federal de Minas Gerais, Belo Horizonte, MG - Brasil

\section{Renata de Almeida Bicalho}

rabicalho@yahoo.com.br

Universidade Federal de Juiz de Fora, Juiz de Fora, MG - Brasil

\begin{abstract}
Resumo
O presente artigo busca analisar a vivência de sexualidade para trabalhadores nãoheterossexuais a partir de suas reflexões acerca dos limites, possibilidades e consequências do processo de assunção de suas sexualidades no ambiente organizacional. Assim, revisitamos pesquisas sobre os homossexuais no ambiente de trabalho, discutimos sobre a diversidade nas organizações e no trabalho, o coming out e a busca de valorização da identidade dos homossexuais. Trata-se de uma pesquisa qualitativa, utilizamos a história oral com foco na trajetória profissional para as entrevistas e apreciamos os dados por meio da análise de conteúdo temática qualitativa por duas categorias: identidade e estigma, e diversidade e coming out. De modo geral, enfatizamos alguns fatores que facilitam ou dificultam a assunção e os impactos desta para os participantes da pesquisa. Destacamos a busca de uma visão reflexiva e humanista quanto aos não-heterossexuais nas organizações e no trabalho.
\end{abstract}

Palavras-chave: Organizações. Trabalho. Não-heterossexuais. Coming out.

\begin{abstract}
This article aims to examine sexuality exercise to not-heterosexual workers starting from their considerations about limits, possibilities and consequences of showing their sexualities at organizational context. Thus, we revisit research on homosexuals in the workplace, we discuss diversity in organizations and at work, coming out and seeking recovery of the identity of homosexuals. This is a qualitative research we used oral history focusing on career paths for interviews, and appreciate the data through qualitative thematic content analysis into two categories: identity and stigma, and diversity and coming out In general, we emphasize some factors that facilitate or hinder the impact of this assumption and to research participants. We highlight a vision reflective and humanistic regarding non-heterosexual in organizations and work.
\end{abstract}


Keywords: Organizations. Work. Not-heterosexuals. Coming out.

\section{Introdução}

O presente artigo busca analisar a vivência de sexualidade para trabalhadores nãoheterossexuais ${ }^{1}$ a partir de suas reflexões acerca dos limites, possibilidades e consequências do processo de assunção de suas sexualidades no ambiente organizacional. Assim, refletir sobre os não-heterossexuais no trabalho implica desconsiderar uma visão asséptica quanto às organizações (SARAIVA; IRIGARAY, 2007) reconhecendo-as como espaços permeados pela sexualidade e por relações de gênero no seu cotidiano.

A homossexualidade, mesmo com os avanços sociais, ainda aparece como uma expressão subalterna ou vista negativamente em diversos segmentos sociais, tendo o preconceito social seja pelo status de doença, perversão ou pecado - produzido o silenciamento e a invisibilidade desta, garantindo o não reconhecimento de direitos sociais e legitimando praticas de inferiorização como a homofobia (PRADO; MACHADO, 2008). Exatamente pela homofobia e heterossexismo, torna-se relevante refletir sobre as causas e razão que levam gays e lésbicas não assumirem sua sexualidade nas organizações (SIQUEIRA; ZAULI-FELLOWS, 2006)

Ela tem sido abordada em diversos ramos do conhecimento como a psicologia, a educação, a saúde, o direito, o serviço social, a comunicação. Geralmente quanto envolvida no âmbito organizacional, a homossexualidade é associada a estudos que consideram a homofobia e a violência nas organizações, o consumo de homossexuais e em questões tocantes às masculinidades hegemônicas no trabalho e nas organizações.

Como alternativas para pesquisa, pode-ser citar: o impacto de se assumir homossexual em empresas públicas e privadas; o desenvolvimento da carreira dos homossexuais; analisar os programas das empresas com foco em justiça organizacional perante as minorias, com destaque para os homossexuais; estudar as relações interpessoais entre homossexuais e heterossexuais; e analisar o cotidiano dos homossexuais no ambiente de trabalho (SIQUEIRA; ZAULI-FELLOWS, 2006).

Tendo em vista a preocupação com as minorias no contexto do trabalho e especificamente com o debate social sobre a homossexualidade, o presente artigo busca entender o processo de assunção ou coming out a partir das experiências e reflexões de trabalhadores nãoheterossexuais, sem desconsiderar que vivem em um ambiente social e organizacional permeado por padrões de sexualidade hegemônicos e heteronormativos. Para tanto, a estrutura do artigo abrangerá alguns apontamentos sobre a diversidade sexual e trabalho e, em seguida, teremos por foco a questão da identidade homossexual e do coming out. Em seguida o foco será metodologia que trata de uma pesquisa qualitativa com entrevistas de história oral como ênfase na trajetória profissional desses trabalhadores. Destacaremos a análise dos dados por duas categorias temáticas: identidade e estigma, e diversidade e coming out. E por fim, algumas considerações destacando a busca de uma visão reflexiva e humanista quanto aos nãoheterossexuais nas organizações e no trabalho.

\section{Diversidade sexual e trabalho: breves apontamentos}

A temática da diversidade sexual nas organizações e no meio acadêmico em administração nacional é recente, porém se trata de um assunto relevante ao envolver aspectos, como ética, justiça organizacional, equidade, políticas de diversidade, satisfação e bem-estar no trabalho. A homossexualidade, no contexto do trabalho, foi pouco estudada pela ciência tanto que falar ou discutir sobre ela continua sendo um tabu, além disso, talvez o tipo de diversidade mais difícil 
de tratar nas organizações seja exatamente aquela relacionada com a homossexualidade (SIQUEIRA; ZAULI-FELLOWS, 2006).

Na produção teórica em administração, a diversidade é geralmente compreendida como aquilo que se distancia da identidade do homem branco, heterossexual e sem deficiências. Os estudos brasileiros geralmente relacionam tal conceito a grupos excluídos ou marginalizados pela sociedade, a partir da situação das minorias. Dessa forma, são incluídos na categoria de diversidade mulheres, não brancos, não-heterossexuais e pessoas com deficiência. Assim, "revela-se, então, um aspecto político da dicotomia normal-diferente, que pode ser traduzido pelo questionamento do que é o normal e do que é o diferente" (FLORES PEREREIRA; ECCEL, 2010, p. 337)

Tratando do preconceito e da diversidade, Mascarenhas (2008) observa que as questões referentes às políticas e práticas da gestão da diversidade no contexto brasileiro não possuem respostas formatadas. Contudo, enfatiza a necessidade de mudar os padrões dominantes na sociedade e nas organizações, bem como sugere que as práticas da gestão da diversidade primeiramente devem revelar a discriminação e como passo seguinte promover a inclusão, principalmente em virtude do preconceito camuflado que caracteriza a sociedade brasileira.

Nessa direção, Saraiva e Irigaray (2009) demonstram a não efetividade das políticas de diversidade perante as minorias, tendo em vista que as políticas organizacionais para promover a diversidade não são efetivas em virtude do preconceito arraigado entre os empregados, de uma permissividade gerencial e da falta de senso coletivo de diversidade. Além de ser encarada instrumentalmente mais como um meio de gerar vantagem competitiva e de adesão dos empregados ao projeto da organização do que uma forma de justiça social ou humanização.

Em uma visão crítica, Alves e Galeão-Silva (2004) ressaltam que a partir do momento em que a contratação de pessoas incluídas em grupos de minorias tornou-se inevitável, as empresas buscaram por meio da gestão da diversidade tornar um conflito político e incontrolável em algo funcional e controlável. Assim, a gestão da diversidade também é um aspecto integrante da ideologia dos administradores em que as questões políticas são tratadas como problemas técnicos. Os autores criticam a visão gerencialista na qual há um determinismo técnico no discurso da gestão da diversidade em que a inclusão das minorias está relacionada a uma lógica produtiva que trata as diferenças como vantagens competitivas que são transformadas num recurso que pode ser gerenciado, ou seja, a diversidade. Assim, "as diferenças são neutralizadas ao serem transportadas para o campo em que todas as coisas são mercadorias" (ALVES; GALEÃO-SILVA, 2004, p. 28).

Como contraponto, para uma real inserção da diversidade nas empresas, Flores-Pereira e Eccel (2010) defendem que a gestão da diversidade nas empresas deve ter uma fundamentação humanística. Logo propõem que, mesmo em organizações lucrativas, deve haver uma relativização de alguns critérios de produtividade para realmente incluir uma multiplicidade de valores, vivências e condições. Ressaltam a importância de se conscientizar de que nas relações sociais em geral, com destaque para aquelas vigentes nas organizações, tende-se a reproduzir um modelo pautado por valores ocidentais, patriarcais, machistas e materialistas, assim determinados atributos são valorizados em detrimento de outros, o que requer que se tenha constante atenção aos próprios preconceitos. Por fim, é relevante que se reflita sobre a dicotomia "normal" e "desviante", a qual confere maior legitimidade social a alguns perante outros, visando à superação dessa dualidade.

Nesse contexto, evidencia-se que os não-heterossexuais, como minoria, tem maior dificuldade para obter seus direitos, inclusive no meio organizacional, do que outras minorias, em virtude 
da homofobia e do heterossexismo (SIQUEIRA; ZAULI-FELLOWS, 2006). Destarte, Siqueira et al. (2009, p 450) dizem que

é contraditório se pensar que, por um lado, as organizações se mostram mais abertas aos homossexuais - desde que não sejam efeminados e nem saiam do padrão social mínimo pré-estabelecido - mas, por outro, o empregado gay teme um possível coming out, seus efeitos e, principalmente, a omissão da empresa que, apesar de lhe conceder alguns benefícios equivalentes aos concedidos aos heterossexuais, não o protege de atos discriminatórios.

Destaca-se que as pesquisas nacionais em administração referentes à diversidade sexual tocam em temas como as estratégias dos homossexuais para sobreviver nas organizações (IRIGARAY, 2007), sobre os efeitos de ser gay nas organizações (FERREIRA; SIQUEIRA, 2007), a homofobia e a violência moral (SIQUEIRA et al., 2009; GARCIA; SOUZA, 2010), o humor como forma de socialização e discriminação (IRIGARAY; SARAIVA; CARRIERI, 2010), violência simbólica em suas trajetórias profissionais (BICALHO et al., 2011), lésbicas e diversidade (IRIGARAY; FREITAS, 2011) e as políticas de diversidade na ótica de trabalhadores gays (DINIZ et al., 2013). Nota-se que as pesquisas relacionadas com a diversidade sexual no trabalho tem se dedicado com maior freqüência ao homossexual masculino, logo seriam relevantes pesquisas que tratem das homossexuais femininas, travestis e transexuais no trabalho. Ademais, demonstram a organização e o trabalho envolvidos pela heteronormatividade, o que pode dificultar a livre expressão de suas sexualidades e o processo de coming out no trabalho que será tratado na sessão seguinte.

\section{Identidade homossexual e coming out}

A sexualidade humana é uma dimensão permeada por significados, interações sociais e institucionais estabelecendo posições sociais, bem como posições identitárias e políticas. As sexualidades são parte de um debate político que influencia a estruturação das hierarquias sociais. Ao longo da história, as sexualidades foram e ainda são objetos de disputa, meios de controle, de violência e de libertação. A heterossexualidade foi considerada uma experiência universal em virtude de um discurso hegemônico que culminava inferiorizando ou tornando invisível qualquer experiência diferente daquilo que é tido como normal. As não heterossexualidades foram condenadas por este discurso hegemônico, que se baseou na religiosidade e no método científico, culminando em desigualdade, exclusão social bem como em menos direitos sociais (PRADO; MACHADO, 2008).

No decorrer do Século XX, a representação da sexualidade passou a ser relacionada com o prazer, com a expressão individual, com a identidade pessoal e com o mercado. Dessa forma diversos grupos - como homossexuais, bissexuais, mulheres e jovens - começaram a contestar várias formas tradicionais (igreja, família, comunidade) e modernas (o Estado, a medicina e a psiquiatria) de regulação da sexualidade por meio de uma política sexual (ADELMAN, 2000). Em tal contexto, é importante destacar que o grande objetivo da luta constituída pela identidade homossexual é a valorização do mesmo, em face de sua condição de marginalização, discriminação, segregação e invisibilidade, com a finalidade de alcançar o reconhecimento social e a legitimidade da sexualidade no contexto dos direitos humanos e civis (FERREIRA, 2007), bem como o papel do movimento gay na busca de visibilidade e da construção de identidades homossexuais valorizadas (FERRARI, 2004).

Considerando os aspectos psicossociais da construção da identidade homossexual, há um processo dinâmico entre os aspectos individuais e sociais, pois no processo de construção identitária, é relevante o reconhecimento desse sujeito no âmbito coletivo e o reconhecimento 
da coletividade pelo sujeito (PEREIRA 2009). Nesse sentido, Nunan (2003) conceitua a identidade homossexual como uma identidade estigmatizada, pela qual vários homossexuais vivenciariam determinados processos de ajustamento pessoal - como a aprendizagem do ponto de vista dos heterossexuais, da desqualificação da homossexualidade, de encobrimento e revelação do estigma - afetando suas perspectivas de mundo e contribuindo para a construção de uma identidade gay. Tal identidade não reduziria o indivíduo à dimensão sexual, porém a homossexualidade teria um forte impacto na construção da identidade, pois "afirmar-se como homossexual afeta grandemente a inserção social e a vivência psíquica destas pessoas, o que significa que não se pode ignorar a importância desta identidade, sobretudo para o movimento gay, fundado na construção de uma identidade possível” (NUNAN, 2003 p. 119).

Para descrever a construção da identidade homossexual, há o modelo de Troiden (1988) no qual o desenvolvimento da identidade homossexual tem quatro estágios: o primeiro é o de sensibilização, no qual o sujeito se sente diferente e marginalizado dos demais, há uma relação com anormalidade e desvio, ocorre geralmente antes da puberdade; o segundo é o estágio de confusão, no qual a possibilidade da homossexualidade pode provocar alguns conflitos internos em virtude da ignorância e do estigma a respeito da homossexualidade, geralmente os indivíduos adotam estratégias de fuga, camuflagem e aceitação parcial de sua sexualidade; o terceiro é o da suposta identidade, nesse estágio há aceitação e revelação apenas para outros homossexuais, ocorrem os primeiros contatos com grupos e locais gays e os primeiros passos para a saída do armário; o último estágio é o de compromisso, no qual a homossexualidade é vista como um modo de vida e a identidade é percebida de modo confortável e pleno. Cabe ressaltar que tais estágios não são lineares e não acontecem da mesma forma para todos os indivíduos, havendo uma variação do modelo em decorrência de fatores como idade ou do momento em que vivenciam este processo.

Deve-se destacar que o rito de "saída do armário" é relevante no processo de construção de uma identidade homossexual, uma vez que reflete o desenvolvimento e a aceitação dessa identidade como parte do autoconceito do indivíduo, bem como a revelação de um status social estigmatizado para amigos, família, outros homossexuais e a sociedade (PEREIRA 2009). Para Nunan (2003, p. 126), tal rito é um evento importante para a aquisição de uma identidade homossexual positiva, sendo que esse passo pode ser considerado um processo complexo de ressocialização para a autoaceitação. Assim, define o coming out como "o processo por meio do qual o homossexual revela sua orientação sexual a outras pessoas (sejam familiares, amigos, colegas de trabalho ou estranhos) tornando-se visível, culturalmente inteligível e desafiando abertamente o discurso sexual hegemônico".

No contexto do trabalho, evidencia-se o estudo de Ragins e Cornwell (2001) focando a assunção da sexualidade com os antecedentes e as consequências da discriminação percebidas por empregados gays e lésbicas. Relacionaram a discriminação percebida com a questão da divulgação ou não da homossexualidade e, como consequências, consideraram as atitudes com a carreira e com o trabalho, bem como e fatores organizacionais como compensações e promoções. Os resultados apontaram no forte impacto das práticas e políticas organizacionais como antecedentes na percepção da discriminação por orientação sexual, destacando as políticas oficiais, a abertura para trazer o parceiro ou a parceira a eventos da empresa. Sobre a assunção, esta seria facilitada ao trabalhar com colegas homossexuais e em empresas com as práticas não discriminatórias, evidenciando também que boa parte da amostra relatou sua condição sexual apenas para algumas pessoas no trabalho.

A pesquisa de Griffith e Hebl (2002) focou a assunção no trabalho considerando, autoaceitação e identidade, atitudes no emprego, satisfação e o apoio organizacional para trabalhadores gays e 
lésbicas. Assim, destacam a relação entre a divulgação da sexualidade no trabalho e satisfação no trabalho, e, além disso, aqueles que recebem apoio e suporte no trabalho se sentem mais satisfeitos e menos estressados. Notou-se também que diferenças individuais, relacionadas com a aceitação e com o grau de assunção, estão relacionadas de modo significativo com a assunção no trabalho. E com relação às políticas de suporte organizacional, os trabalhadores gays e as lésbicas são mais propensos a tornar pública sua condição quando as organizações têm políticas oficiais que os protegem, demonstram suporte ativo para atividades gays ou lésbicas, e oferecem treinamentos voltados especificamente para a inclusão desses indivíduos.

No tocante a vivências específicas de lésbicas no trabalho, destaca-se o trabalho de Duffy (2010) que explora no contexto irlandês o trabalho de sete enfermeiras lésbicas, evidenciando que o ambiente institucional da medicina reflete as normas heterossexuais. Assim, no trabalho, elas se deparam com a lesbofobia e com a falta de apoio social e compreensão a respeito de suas sexualidades. Desse modo, tais enfermeiras irlandesas permanecem no "armário" e em uma situação de invisibilidade, tendo como consequência o isolamento social de algumas delas. Demonstra-se que ser "si mesmo" ou agir de forma espontânea é difícil para as enfermeiras lésbicas que trabalham na cultura heteronormativa de hospitais irlandeses.

No contexto brasileiro, sobre o coming out nas organizações, Ferreira e Siqueira (2007) realizaram entrevistas com 15 homossexuais masculinos na cidade de Brasília. Destaca-se que ambientes mais favoráveis à diversidade impulsionam o processo de saída do "armário", ao passo que, ambientes mais rígidos, inflexíveis e não aberto à diversidade, favorecem para que o homossexual permaneça no "armário". A decisão de permanecer no "armário" é decorrente de que os homossexuais, tendo revelado sua orientação sexual, serão foco de piadas, chacotas e brincadeiras, que impactarão negativamente em suas relações interpessoais no ambiente de trabalho. Além disso, impacta nessa decisão, a crença de que tendo revelado sua orientação, não terão oportunidades de crescimento e ascensão profissional. Ademais, sobre as barreiras ao crescimento profissional no ambiente de trabalho, é notório que tais barreiras existem de forma velada e declarada, como as situações nas quais há ameaças de perda de emprego, de perda de função, de assédio moral e outras que se relacionam com o crescimento profissional e, inclusive, com a manutenção do próprio emprego.

\section{Metodologia}

Trata-se de uma pesquisa qualitativa, sendo esta a mais adequada por ter como foco a subjetividade de trabalhadores não-heterossexuais durantes suas trajetórias profissionais, assim Haguette (2003, p. 63) enfatiza que a pesquisa qualitativa é útil ao se buscar "uma compreensão profunda de certos fenômenos sociais apoiados no pressuposto da maior relevância do aspecto subjetivo face à configuração das estruturas societais".

Com relação aos participantes da pesquisa são doze não-heterossexuais, selecionados por contatos pessoais e indicações, conforme a seguir: uma mulher bissexual, seis homens gays, cinco lésbicas. Conforme Picazio (1998), adotaram-se, neste estudo, os seguintes conceitos: os homossexuais masculinos e femininos são aqueles que possuem desejos afetivos e sexuais por alguém do mesmo sexo; já o/a bissexual sente desejos afetivos e sexuais por pessoas de ambos os sexos. Ainda sobre o perfil dos sujeitos da pesquisa, possuem idade média de aproximadamente 31 anos e tempo de trabalho médio de aproximadamente 11 anos. A caracterização dos entrevistados segue no quadro 1. 


\begin{tabular}{|c|c|c|c|c|c|c|c|}
\hline Código & Característica & Idade & Escolaridade & Organização & $\begin{array}{l}\text { Setor da } \\
\text { organização }\end{array}$ & $\begin{array}{l}\text { Cargo/ } \\
\text { Ocupação }\end{array}$ & $\begin{array}{l}\text { Tempo de } \\
\text { trabalho }\end{array}$ \\
\hline EB & $\begin{array}{l}\text { Bissexual } \\
\text { feminina }\end{array}$ & 26 & Especialização & Privada & Beleza & Assistente de tatuagem & 3 \\
\hline EG1 & $\begin{array}{l}\text { Homossexual } \\
\text { masculino }\end{array}$ & 30 & Superior & Privada & Bancário & Gerente & 11 \\
\hline EG2 & $\begin{array}{l}\text { Homossexual } \\
\text { masculino }\end{array}$ & 24 & Superior & Privada & Advocacia & $\begin{array}{l}\text { Advogado e supervisor } \\
\text { de call center }\end{array}$ & 4 \\
\hline EG3 & $\begin{array}{l}\text { Homossexual } \\
\text { masculino }\end{array}$ & 37 & $\begin{array}{l}\text { Superior } \\
\text { incompleto }\end{array}$ & Privada & Informática & Analista de suporte & 19 \\
\hline EG4 & $\begin{array}{l}\text { Homossexual } \\
\text { masculino }\end{array}$ & 35 & Superior & Privada & Hospitalar & Assistente contábil & 22 \\
\hline EG5 & $\begin{array}{l}\text { Homossexual } \\
\text { masculino }\end{array}$ & 33 & Técnico & Privada & Vestuário & Técnico contábil & 12 \\
\hline EG6 & $\begin{array}{l}\text { Homossexual } \\
\text { masculino }\end{array}$ & 36 & Superior & Pública & Educacional & $\begin{array}{l}\text { Assistente de secretaria } \\
\text { terceirizado }\end{array}$ & 22 \\
\hline EL1 & $\begin{array}{l}\text { Homossexual } \\
\text { feminina }\end{array}$ & 25 & Ensino médio & Privada & Call center & Telemarketing & 7 \\
\hline EL2 & $\begin{array}{l}\text { Homossexual } \\
\text { feminina }\end{array}$ & 24 & $\begin{array}{l}\text { Superior } \\
\text { incompleto }\end{array}$ & Privada & Gráfico & Designer gráfica & 5 \\
\hline EL3 & $\begin{array}{l}\text { Homossexual } \\
\text { feminina }\end{array}$ & 39 & $\begin{array}{l}\text { Ensino } \\
\text { fundamental }\end{array}$ & Privada & $\begin{array}{l}\text { Comércio } \\
\text { (Restaurante) }\end{array}$ & Auxiliar de cozinha & 15 \\
\hline EL4 & $\begin{array}{l}\text { Homossexual } \\
\text { feminina }\end{array}$ & 38 & Técnico & Privada & Hospitalar & $\begin{array}{ll}\text { Técnica } & \text { em } \\
\text { enfermagem } & \end{array}$ & 14 \\
\hline EL5 & $\begin{array}{l}\text { Homossexual } \\
\text { feminina }\end{array}$ & 28 & Superior & Privada & Saúde & Fisioterapeuta & 4 \\
\hline
\end{tabular}

Quadro 1 - Caracterização dos entrevistados

Fonte: Elaborado pelos autores a partir de dados da pesquisa

O método de levantamento dos dados utilizado foi a história oral com foco em suas trajetórias no trabalho e nas organizações conforme Meihy (1996). Assim, tratando especificamente da pesquisa organizacional e da história oral, Ichikawa e Santos (2006) destacam que as entrevistas obtidas por meio da história oral podem demonstrar a liberdade que as pessoas têm e elas auxiliam na observação do funcionamento dos sistemas normativos das organizações ao possibilitar que os excluídos sejam ouvidos.

As entrevistas foram realizadas em Juiz de Fora, cidade na qual os entrevistados residem, tendo sido gravadas com a permissão dos entrevistados e integralmente transcritas. Para os efeitos da análise dos desta pesquisa, realizou-se leituras das transcrições e adotou-se o critério semântico para definição das categorias temáticas, consoante Bardin (2011). Nessa direção, Franco (2003, p. 14) destaca que a análise de conteúdo baseia-se em elementos de uma concepção crítica e 
dinâmica da linguagem como a semântica, "aqui entendida não apenas como o estudo da língua, em geral, mas, como, a busca descritiva, analítica e interpretativa do sentido que um indivíduo (ou diferentes grupos) atribuem às mensagens verbais e simbólicas".

\section{Análise dos dados}

A análise está subdivida em duas categorias: a primeira trata da identidade, estigma e da dificuldade de aceitação dos não-heterossexuais e a segunda tem por foco a diversidade e as considerações sobre o coming out no trabalho.

\section{Identidade e estigma}

Começaremos essa análise versando sobre a identidade e o estigma na trajetória de gays e lésbicas. 0 estigma é intenso principalmente na fase de descoberta ou quando não se aceitam plenamente como evidenciado, conforme a seguir:

É complicado, é complicado, é uma coisa que eu não gostaria de ser. É como um livro que eu acabei de ler, acabei de ler não, já li bastante tempo, ele fala muito desse ímpeto sexual, que ele é mais forte do que nós imaginamos. Então, nos trazemos de vidas passadas, então você não consegue segurar isso, então se eu tenho essa carga, se eu tenho esse erro, eu não posso me modificar, eu tenho que saber aceitar, só que a aceitação muita vezes é complicado, minha família não sabe. [...]

Aceitação, para você, é complicada também?

É complicada.

Sua auto-aceitação?

Eu demorei muito para me autoaceitar. E assim mesmo, tem dias que eu não aceito. Se eu me aceitasse por completo, eu falava rasgadamente para minha família toda, eu sou veado. Quer dizer eu não me aceitei porque eu não falei (EG4).

É evidente a dificuldade de auto-aceitarão ao ressaltar que não gostaria de ser homossexual como destacado nos estágios iniciais do modelo de Troiden (1988), o entrevistado relaciona esse sentimento com sua religião, assim destaca sua homossexualidade como uma carga e como um erro. Conta sobre a dificuldade de se abrir com sua família e crê que não se aceita de modo pleno, por nunca ter saído do "armário" para sua família. A seguir, os entrevistados destacam sobre ser gay na sociedade.

[...] Já teve momentos de eu falar assim: por que eu não nasci hetero?! Seria tudo tão mais fácil, eu estaria namorando, andando com a minha namorada... (EG5).

[...] Eu não queria ter essa vida não. Se falar assim: você quer ser hetero ou ser gay? Eu quero ser hetero. É muito difícil, é muito complicado, é estranho. Você não é completo. Está te faltando alguma coisa. Você vive muita solidão, você fica sozinho, por mais que você tenha amigos. Eu acho que não é uma vida legal. Não é uma vida que te traz, é. Tudo que foge da regra, que vira exceção, já é difícil, já e complicado, já está na contramão. Saiu do padrão, já não é uma coisa, vamos dizer, não mantém uma sintonia. É a mesma coisa de uma música, de uma máquina, de um teclado, estragou uma tecla, o texto já vai sair prejudicado, faltando uma letra no texto todo. Então eu acho que o gay, na sociedade, no geral, seria essa tecla que estragou. Alguém que está fora, que está na contramão da realidade (EG6).

0 entrevistado 5 conta que houve momentos em que ele preferia ter nascido heterossexual, como se fosse algo mais adequado ou apropriado socialmente, todavia esse é um pensamento já 
superado em sua trajetória, demonstrando sua auto-aceitação e o estágio de comprometimento conforme Troiden (1988). Em contraste, o 6 compartilha aquele sentimento, só que ainda de forma intensa, algo próximo ao estágio de sensibilização descrito por Troiden (1988). Assim, ele assume totalmente o ponto de vista heteronormativo ao dizer que preferia ser heterossexual a homossexual, destacando todas as dificuldades e desvantagens em ser homossexual, comparando o gay à tecla que deu errado na sociedade, o que remete ao estigma da homossexualidade (GOFFMAN, 1975).

No trecho adiante, veja sobre as restrições de comportamento:

[...] Eu não posso ficar assumindo para todo mundo. Sabe, eu mesma, às vezes, fico com vergonha...

Assim, quando? 0 que acontece?

Por causa da minha família, minha família tem preconceito, não aceita até hoje. Por mim não, por mim, eu saía agarrando a minha mulher, beijando... Não aceita. Eu me sinto reprimida.

Como você se sente a respeito disso?

Me sinto mal cara, mal. Sem poder fazer nada. Ela chora, me critica, briga (EL3).

Nota-se a dificuldade de auto-aceitação e o estigma na identidade da participante quando destaca que, às vezes, sente vergonha em ser lésbica e se sente reprimida em virtude das restrições de comportamento imposta por grupos sociais como sua família.

Consideremos sobre as identidades não hegemônicas:

Nossa, há um tempo atrás, eu falaria para você que é frustrante (risos). Hoje em dia, eu acho que, para mim, ser bissexual é igual eu ser mulher, ser negra, ser qualquer coisa que não seja normal em alguns padrões que as pessoas guardam em rotulozinhos de certo e como você passa preconceito de algumas pessoas. Mas quando você encontra alguém que te trate com respeito, que te trate com carinho, que seja seu companheiro, sua companheira, sua amiga ou seu amigo, sem diferenciar sua orientação sexual ou qualquer coisa que você tenha de diferente e não considerar a sua orientação sexual, é igual qualquer outra coisa, normal, simples. Problema é que nem sempre você passa por essa tranquilidade (EB).

No trecho acima, destaca-se uma visão anterior negativa sobre a bissexualidade, o que pode ser associado ao estigma na sexualidade como abordado por Nunan (2003) e, atualmente, uma que a considera como uma sexualidade excluída assim como outros aspectos pessoais não hegemônicos da participante, tal como ser mulher e ser negra, ou seja, identidades que fogem aos padrões socialmente valorizados.

\section{Diversidade e Coming out}

Nesta categoria, analisaremos sobre as políticas voltadas à diversidade sexual, a questão da assunção, as considerações sobre assumir ou não assumir a homossexualidade, a cultura de propícia ou não à diversidade no ambiente de trabalho e os impactos do coming out.

Primeiramente, é relevante destacar a importância de políticas para a inclusão dos nãoheterossexuais nas organizações e que as mesmas promovam a educação, a equidade, a não discriminação e um ambiente de trabalho que proporcione qualidade de vida. Logo, é importante mencionar o desconhecimento da maioria dos entrevistados sobre essas políticas visto que, provavelmente, a realidade de Juiz de Fora ainda não abranja as políticas de diversidade voltadas para a orientação sexual e também o fato da maioria dos entrevistados 
trabalharem em empresas médias ou pequenas. Nesse sentido, é interessante a fala seguinte do homossexual que trabalha em um grande banco privado.

Olha só, quando eu fiz até monografia da faculdade, eu fiz sobre responsabilidade social corporativa, então lá tudo que eu me aprofundei, estudei, fala que a organização não tem discernimento em relação a contratar se a sexualidade da pessoa é diferenciada ou não, que ela é uma organização que engloba todos os profissionais, mas isso é visível dentro da organização, tanto que na minha agência eu não sou o único, tem outros lá. Então, isso não é um critério para eliminar ou deixar de contratar no caso, eu acho que, a organização, nesse sentido, ela cumpre sim. Só que lá dentro que é difícil você peneirar, porque nem todos os profissionais que estão lá são pessoas que são adeptas a aceitar uma pessoa que tem uma opção diferente, o preconceito vai existir porque ela contrata diversas pessoas com diversas opções sexuais. Agora, a questão das pessoas se entenderem ali dentro vai ser uma questão de convivência mesmo (EG1).

O depoente conta que seu trabalho de conclusão de curso foi dedicado à questão da responsabilidade social e informa que, em sua organização, não haveria discriminação no processo seletivo, tanto que não é o único homossexual de sua agência. Porém, diz que não são favoráveis todos seus colegas de trabalho à diversidade sexual e destaca que não há nada que proteja os homossexuais no cotidiano em seu trabalho, no caso normas ou políticas efetivas, como discutido por Saraiva e Irigaray (2007).

Tratando do coming out na organização, pode haver uma cultura mais aberta à diversidade, o que facilitaria esse processo, como sugerido abaixo.

... como eu te disse, depende muito do clima, de onde você trabalha, eu acho que depende muito da visão das pessoas com as quais você trabalha... (EG1)

Sendo muito sincero, dependendo do tipo de empresa que você trabalha, o pessoal é muito mente aberta (EG3).

Os entrevistados compartilham da mesma opinião, de que a cultura da diversidade é relativa a cada empresa ou depende das pessoas com as quais se trabalha, corroborando os achados de Ragins e Cornwell (2001) e Ferreira e Siqueira (2007).

Sobre a questão de assumir, há de se considerar alguns aspectos como abaixo:

Eu trabalhei muito com pessoas gays também. Eu tive essa sorte. Então, foi muito tranquilo... (EL1)

[...] no hospital dá muito homossexual. Então, eu acho que é um ambiente muito fácil das pessoas aceitarem, porque dá demais. Sempre tem ou um homem ou uma mulher, sempre tem alguém no plantão que é. No meu mesmo, não é só eu (EL4).

[...] Mas, durante todo o tempo em que eu assumi a minha sexualidade no trabalho, foi em locais que eu tinha essa liberdade que era estúdio de dança onde tinham muitos homossexuais do sexo feminino e masculino. No (nome de órgão ligado à área de cultura) que era um lugar mais tranquilo, foi lá até que eu me assumi, que eu saí do armário pela primeira vez, falar sobre sexualidade... (EB). [...] Ninguém me critica, me aceitam do jeito que eu sou.

As pessoas sabem?

Sabem, me aceitam, gostam de mim. Nada contra (EL3).

Para essas trabalhadoras, a vivência da sexualidade é facilitada no ambiente organizacional ao 
conviverem com outros trabalhadores homossexuais ou em ambientes que seriam mais abertos à sexualidade como aquele da enfermagem ou do setor artístico. Logo, tais observações corroboram as análises de Irigaray e Freitas (2009) em que trabalhar em um ambiente aberto e com outros homossexuais tornariam o ambiente de trabalho mais confortável.

Há uma consideração relevante nessa questão da assunção:

[...] Então hoje algumas pessoas sabem no meu trabalho, mas foram pessoas que eu me identifiquei durante a trajetória no meu serviço, são pessoas que, de uma forma ou outra, eu senti confiança de falar sobre isso... Então, principalmente, quando você é homossexual é difícil você escolher, você saber se é a pessoa ideal para você se abrir ou não... foi assim pessoas que eu achei que poderia confiar e realmente confiei e não me decepcionei com isso (EG1).

0 entrevistado ressalta que se assumiu para algumas pessoas no seu trabalho, porque foram pessoas com as quais ele se identificou ou que lhe inspiraram confiança. Além disso, destaca que é difícil saber com quem falar sobre isso o que, de certa forma, requer identificação, análise e talvez intuição. Por fim, destaca que as experiências foram positivas com tais pessoas.

A percepção sobre a abertura quanto à diversidade na empresa influencia na decisão de se assumir ou não no trabalho, como abaixo.

Bom, eu entrei no estúdio de tatuagem acreditando que era um lugar extremamente moderno onde todo mundo tinha liberdade para falar e fazer o que quisesse. Eu comecei a me dar conta que, apesar de que a esposa do meu chefe ser uma pessoa muito liberal, ele é um tanto quanto homofóbico, é uma homofobia muito velada. Mas, ele é do tipo, "não vou deixar de tatuar um gay, não vou deixar de tatuar uma lésbica, mas eu prefiro que ele nem chegue perto do meu filho, pode influenciá-lo mal" [...]. Eu notei que alguns clientes eram um pouco homofóbicos, eu comecei a ficar com um pouco de medo de falar alguma coisa e perder meu emprego por causa disso [...] Então para não ter problemas e para em momento algum ele falar "puxa vida, a (nome da entrevistada) me decepcionou por causa disso", eu prefiro deixar quieto. Para mim, é até frustrante, desde que eu assumi, eu nunca deixei de falar o que eu sentia, o que eu pensava (EB).

O preconceito no trabalho atual da entrevistada é sutil sendo expresso pela homofobia velada de seu chefe e de alguns clientes, como analisado por Bicalho et al. (2011) a respeito da violência simbólica. Em função disso, percebe que não pode agir de modo espontâneo no seu ambiente de trabalho, começou a tomar cuidado com o que diz e o impacto dessa situação é sua frustração, invisibilidade e isolamento pela heteronormatividade envolta no ambiente (DUFFY, 2010).

O próximo depoimento também relaciona a questão do não dito e da não assunção com a cultura de diversidade da empresa

Essa outra agora já é um pouco mais complicado porque essa é uma empresa familiar e a gente percebe no caso da gerência algumas coisas meio complicadas de pegar e falar de cara. Embora, eles já saibam, é muito complicado você chegar de cara e falar isso porque tem muita gente que se assusta e acha que você é pervertido etc. e não é bem assim...

\section{De certa forma, você tenta esconder a sua sexualidade?}

Não, não escondo porque quem pergunta, eu falo. Não tem isso, eu só acho que ali existem algumas pessoas que não tem a mente tão aberta como da outra empresa, são pessoas criadas numa geração diferente. Então, elas acham que 
homem tem que ser hetero sempre, mulher tem que ser hetero sempre (EG3).

Por trabalhar atualmente em uma empresa menos favorável à diversidade em comparação com outra empresa na qual já trabalhou, esse indivíduo prefere não falar abertamente sobre sua sexualidade e apenas fala quando é questionado, pois crê que as pessoas tem a visão de que o homossexual é um pervertido, o que demonstra a ligação entre homossexualidade e promiscuidade na sociedade, e, assim, não são abertas à diversidade, destacando aspectos como o estigma à homossexualidade (GOFFMAN, 1975).

Há também aquelas áreas profissionais nas quais haveria pouca aceitação da homossexualidade como o Direito.

[...] os próprios clientes, os próprios colegas de trabalho, as próprias pessoas que tem que lidar no meio do Direito, acabam fazendo alguma piadinha, acabam não respeitando, acabam sendo muito preconceituosas, porque acham, ainda tem aquela imagem arcaica que é um profissional que teria que ser sério, um profissional que, e é o contrário, é um profissional que luta pelos direitos que luta pelos deveres das pessoas, que luta por uma justiça, que seria o que mais que teria que ser igualado, no caso igualado à diversidade, igualado aos direitos, e não, é o que mais sofre preconceito.

\section{Você acha que é o que mais sofre preconceito?}

Eu acho que é uma profissão assim por ser, pelas pessoas terem em mente que é uma profissão antiga, que está ligada ao poder, à justiça, a uma forma de fazer valer os direitos das pessoas, ainda não poderia ser uma pessoa no caso um homossexual. Teria que ser uma pessoa séria, não que o homossexual não fosse, mas é o que a sociedade do direito cobra uma pessoa séria, uma pessoa que tem aquele ar assim de mais respeitada, uma pessoa que não pode haver um deslize, vamos dizer assim.

\section{Uma pessoa assim, no caso, que as outras nunca desconfiaram que fosse um homossexual?}

Sim. (EG2)

O entrevistado nota uma contradição em sua área devido ao ideal de justiça e igualdade que não ocorre na prática, assim diz que, para se manter como um profissional respeitado na área de Direito, não pode assumir sua homossexualidade. Ainda, acredita que o grande preconceito que visualiza em sua área seja decorrente de que as pessoas acreditam que um advogado deveria ser uma pessoa séria e que o homossexual não seria considerado sério o bastante a ponto de ser competente para poder torna-se um bom profissional, como discutido por Bicalho et al. (2011) o preconceito à homossexualidade pode desvalorizar o profissional.

É interessante a seguinte análise tratando sobre ter assumido, mas depois ter considerado que não deveria.

[...] além dele ser o gerente da empresa, eu acho que tinha aquela situação hierárquica, e eu não era gerente, não tinha esse cargo, era um simples funcionário, então quando você não tem um cargo que tenha peso, peso de decisão, por exemplo, de mandar você embora ou não, ou saber que você tá tendo um bom retorno ou alguma coisa para empresa, era complicado, então foi o que aconteceu. Ele podia, eu não, então eu acho que ali foi um pouco de erro de ter sido assim muito aberto... (EG3).

Como eu não sou daqui, eu estou acostumado com o jeito carioca, de conversar, chegar, brincar, contar a sua vida inteira em um dia. Eu cheguei aqui, vi que o pessoal de minas é um pouquinho mais recatado, eles se assustaram um pouco 
com isso. Ai eu tive que frear, pisei literalmente no freio, para me acostumar com o como é feito com ele até me adaptar. Hoje em dia, eu acho que eu to mais mineiro que carioca, acho que eu aprendi um pouquinho a ter essa coisa do pé atrás... (EG3).

Na primeira fala, o entrevistado conta a história de um antigo gerente homossexual e relaciona a história ao seu comportamento na empresa, destacando que deveria ter um comportamento mais contido ou fechado, pois diferentemente do outro não tinha um cargo de poder ou de decisão. Na segunda fala, por algumas reações negativas das pessoas, ele começa a agir com maior desconfiança e menor espontaneidade nos assuntos referentes à sua homossexualidade, em decorrência do heterossexismo (SIQUEIRA; ZAULI-FELLOWS, 2006).

A seguinte história também demonstra a relação entre a barreira e a não aceitação do homossexual assumido no ambiente de trabalho.

[...] já conheci pessoas que tipo trabalham em (nome de empresa do setor bancário) e que são concursadas há muitos anos, vive os últimos anos em licença médica em depressão porque o superior não aceita a posição dele, porque é uma pessoa esclarecida, esclarecida assim fala abertamente a posição, e não passa dali, então quer dizer varia muito de lugar para lugar e depende muito de com quem você está convivendo, porque tem pessoas abertas que aceitam que vêem você com outro olhos, agora de $100 \%$, noventa não vê isso... (EG4)

Conforme o trecho acima, o indivíduo relata que, por ser assumido no trabalho, esse profissional não consegue crescer na carreira, o que remete às observações de Ferreira e Siqueira (2007) quanto à ascensão hierárquica, tendo como consequência a depressão pela não aceitação da sua sexualidade no trabalho. 0 próximo depoimento é também nessa direção, porém há uma relativização:

Eu acho que muito depende da função, está muito aberto sim, muito fácil de lidar, mas infelizmente em algumas funções mais valorizadas, o que eu vejo assim que as pessoas que não falam, que não se abrem, as pessoas, igual eu falei, mais discretas que não são tão afeminadas, tem mais facilidade. Se for uma função assim mais baixa, é mais fácil de você entrar na empresa... (EG2).

De acordo com o entrevistado, a relativização do crescimento na carreira está relacionada com o tipo de cargo a ser ocupado, poderia haver maior dificuldade em ocupar cargos mais elevados hierarquicamente, principalmente para os homossexuais assumidos ou efeminados (ECCEL; SARAIVA, 2009). Assim, a estratégia para ascensão hierárquica pode envolver a não assunção da sexualidade.

Nesse contexto, o homossexual pode ser excluído dos círculos sociais o que acaba dificultando seu crescimento nas empresas.

Na parte onde que eu estou por ser uma filantropia, por não ter patrão, por não ter nada, é a panelinha que reina, então se você já não faz parte da panelinha, você jamais vai reinar e por ter administradores do tempo da onça que não admitem esse tipo de liberdade que hoje nós temos, eles jamais colocariam alguém, subiriam a um posto alguém desse nível.

\section{No caso alguém homossexual ou uma mulher lésbica, talvez?}

Não, não entraria... (EG4)

O entrevistado conta sobre a não aceitação em seu trabalho e acaba não tendo oportunidades de crescimento profissional, como discutido por Garcia e Souza (2010). Além disso, salienta que, 
por trabalhar numa organização filantropa, a dimensão política é muito forte e, dessa forma, em virtude do preconceito dos administradores e, sendo assim, por não fazer parte do círculo social da alta administração, sente grande dificuldade no seu crescimento profissional.

O receio da fisioterapeuta em não conquistar novos clientes faz com que prefira a não assunção.

[...] Porque eu acho assim mesmo que as pessoas desconfiem. Eu acho que os pacientes que eu tenho hoje, se amanhã eu falar para eles que eu sou, eles não vão deixar de fazer fisioterapia comigo. A questão é assim, é conquistar novos clientes e ter essa fama. É isso que é o meu receio, eu quero ter a fama pelo o que eu sou como profissional e não o que eu faço entre quatro paredes (EL5).

Como mencionado, a lésbica prefere não se assumir por causa da possível dificuldade de conseguir novos clientes, em virtude do estigma social da homossexualidade. 0 receio decorre de que, como lésbica, as pessoas possam crer que ela não é uma profissional de confiança ou séria. Nesse sentido, a sexualidade atua desqualificando a profissional, como abordado por Bicalho et al. (2011).

Apesar dessas dificuldades, devemos destacar nesta discussão os impactos positivos do coming out, tendo sido ressaltada a melhoria das relações interpessoais ou o apoio dos colegas no ambiente de trabalho.

[...] quando eu cheguei na empresa, novo, estava há meses na empresa, e eu cheguei, chamei o pessoal para contar sobre a minha orientação porque aquilo me incomodava e eu achava que o pessoal ia me mandar embora para casa, e assim, as primeiras vezes, vários funcionários, lá, "ah não que isso, a gente sabe como que é, a gente tem pessoas para conviver, a gente dá apoio, etc." e aquilo ficou muito feliz, porque eu tinha uma base para me sustentar e eu achava que nem isso, eu iria ter (EG3).

Esse sujeito descreve a situação em que decidiu "sair do armário" em um trabalho e a satisfação por ter recebido apoio dos colegas.

Outro impacto positivo está relacionado com o sentir-se bem, maior liberdade, um agir mais natural e tranquilidade.

[...] Para mim, eu te digo que faz certa diferença, porque eu não gosto de manter nada escondido, se está escondido parece que eu estou fazendo alguma coisa errada. Principalmente no ambiente de trabalho, seu trabalho é sua segunda casa... 0 fato deles me darem essa liberdade eu me sinto muito bem por ser assumida no meu trabalho (EL2).

Melhorou muito. Depois que a gente se assume, melhora muito. A gente fica solta porque, antes, a gente ficava com medo de alguém chegar e, às vezes, te ver em algum lugar e acabar comentando "ah, eu vi fulano, eu vi a (nome da entrevistada) numa boate gay com uma menina”. Aí, você já fica assim. Hoje, se alguém chegar e comentar, é natural para todo mundo (EL4).

Essas profissionais ressaltam os impactos positivos do coming out, logo cabe destacar a maior liberdade e espontaneidade de comportamento. Isso também implica menos stress para as homossexuais no ambiente de trabalho, como observado por Griffith e Hebl (2002).

\section{Considerações finais}

0 presente artigo busca analisar a vivência de sexualidade para trabalhadores nãoheterossexuais a partir de suas reflexões acerca dos limites, possibilidades e consequências do 
processo de assunção de suas sexualidades no ambiente organizacional. Revisitamos pesquisas sobre diversidade sexual e trabalhos com foco no coming out e na identidade homossexual. Entrevistamos doze não-heterossexuais por meio da história oral com ênfase na trajetória profissional e analisamos os dados por meio da análise de conteúdo temática e qualitativa. Assim, nesta pesquisa, salientamos que a assunção é facilitada quando os não-heterossexuais trabalham com outros não-heterossexuais e com simpatizantes ou em meios onde há uma melhor aceitação, como a enfermagem ou o meio cultural e das artes, sendo a cultura de diversidade relativa a cada empresa. São notórios fatores como a confiança e a identificação com a outra pessoa no processo do coming out. Já enfocando o não assumir, considera-se a mudança negativa nas relações interpessoais, o receio do estigma profissional e, de certa forma, também o conservadorismo de áreas específicas como o Direito.

Há de se levar em conta também as relações de poder sendo que o homossexual com poder de decisão ou em um cargo estratégico teria mais facilidade no coming out do que aquele num cargo operacional. E os impactos do coming out, sendo a empresa aberta à diversidade, são tidos como positivos para a melhoria nas relações interpessoais, o apoio dos colegas, amizades com maior confiança, o agir natural e espontâneo, liberdade de comportamento, tranquilidade e menos stress.

Tratando do crescimento e das oportunidades na organização, é destacado que os homossexuais podem ser preteridos em favor dos heterossexuais. Evidenciam-se as barreiras para 0 crescimento em cargos elevados hierarquicamente, principalmente quando o homossexual é assumido ou apresenta trejeitos efeminados. Nesse sentido, o homossexual também é excluído dessas oportunidades por não fazer parte do círculo social da alta administração em virtude de ser "diferente" e do preconceito arraigado.

Nesse contexto, é importante também refletir sobre o papel dos gestores e da gestão da diversidade ao buscar numa perspectiva humanista a conscientização quanto aos preconceitos arraigados nas organizações de modo que se trabalhe com a educação e a reflexão para possibilitar que os/as profissionais não sejam desvalorizados ou enfrentem barreiras quanto à sua sexualidade.

Por fim, destacamos a importância da valorização da identidade dos não-heterossexuais em face das discriminações e estigmatizações que experimentam no contexto social e organizacional. Ademais, seria interessante que pesquisas sobre o coming out no trabalho fossem realizadas em outras regiões e cidades do Brasil, ou ainda em setores específicos.

\section{Notas}

1 Tal como em Santos (2013, p. 8), neste trabalho, “[...] visto que se a heterossexualidade é a identificação dominante, 'não-heterossexual' designará, então, todas as identificações sexuais que recusam e desafiam essa mesmíssima norma". 


\section{Referências}

ADELMAN, M. Paradoxos da identidade: a política de orientação sexual no século XX. Revista de Sociologia e Política, Curitiba, 14, n. 0, p. 163-171. jun. 2000.

BARDIN. L. Análise de conteúdo. Lisboa: Edições 70, 2011. 280 p.

BICALHO, R. A.; DINIZ, A. P. R.; CARRIERI, A. P. ; SOUZA, M. M. P. Symbolic violence and homosexuality: a study in Brazilian major cities. Far East Journal of Psychology and Business, Berkeley, v. 5, n. 1, p. 1-22, Oct. 2011.

DINIZ, A. P. R.; CARRIERI, A. P.; GANDRA, G.; BICALHO, R. A. Políticas de diversidade nas organizações: as relações de trabalho comentadas por trabalhadores homossexuais. Revista Economia \& Gestão, Belo Horizonte, v. 13, n. 31, p. 93-114, jan./abr. 2013

DUFFY, M. Diversity in the Irish workplace - lesbian woman's experience as nurses. The International Journal of Diversity in Organisations, Communities and Nations, Champaign, v. 10, n. 3, p. 231-241, July 2010.

ECCEL, C. S.; SARAIVA, L. A. S. Masculinidade, auto-imagem e preconceito: um estudo das representações sociais de homossexuais. In: ENCONTRO ANUAL DA ASSOCIAÇÃO NACIONAL DE PÓS-GRADUAÇÃO E PESQUISA EM ADMINISTRAÇÃO, XXXIII, 2009, São Paulo. Anais... São Paulo: ANPAD, 2009.

FERRARI, A. Revisitando o passado e construindo o presente: o movimento gay como espaço educativo. Revista Brasileira de Educação, Rio de Janeiro, v. 25, p. 105-115, abr. 2004.

FERREIRA, R. C. 0 gay no ambiente de trabalho: análise dos efeitos de ser gay nas organizações contemporâneas. 126 f. Dissertação (Mestrado em Administração) - Faculdade de Economia, Administração, Contabilidade e Ciências da Informação e da Documentação, Universidade de Brasília, Brasília 2007.

FERREIRA, R. C.; SIQUEIRA, M.V. S. O gay no ambiente de trabalho: análise dos efeitos de ser gay nas organizações contemporâneas. In: ENCONTRO ANUAL DA ASSOCIAÇÃO NACIONAL DE PÓSGRADUAÇÃO E PESQUISA EM ADMINISTRAÇÃO, Rio de Janeiro, XXXI, Anais... Rio de Janeiro: ANPAD, 2007.

FLORES-PEREIRA, M. T.; ECCEL, C. S. Diversidade nas organizações: uma introdução ao tema. In. BITENCOURT, C. (Org.) Gestão contemporânea de pessoas: novas práticas, conceitos tradicionais. Porto Alegre: Bookman, 2010. p. 335-352.

FRANCO, M. L. P. B. Análise de conteúdo. Brasília: Plano, 2003. 78 p.

GARCIA, A.; SOUZA, E. M. Sexualidade e trabalho: estudo sobre a discriminação de homossexuais masculinos no setor bancário. Revista de Administração Pública, Rio de Janeiro, v. 44, n. 6, p. 1353- 1377, nov./dez. 2010.

GOFFMAN, E. Estigma: notas sobre a manipulação da identidade deteriorada. Rio de Janeiro: Zahar, 1975. 160 p.

GRIFFITH, K. H.; HEBL, M. R. The disclosure dilemma for gay men and lesbians: "coming out" at work. Journal of Applied Psychology, Washington, v. 87, n. 6, p. 1191-1199, Dec. 2002. 
HAGUETTE, T. M. F. Metodologias qualitativas na sociologia. Petrópolis: Vozes, 2003. 224 p.

ICHIKAWA, E. Y.; SANTOS, L. W. Contribuições da história oral à pesquisa organizacional. In: GODOI, C. K.; BANDEIRA-DE-MELLO, R.; SILVA, A.B. (Org). Pesquisa qualitativa em estudos organizacionais: paradigmas, estratégias e métodos. São Paulo: Saraiva, 2006. p. 181-206.

IRIGARAY, H. A. R. Estratégia de sobrevivência dos gays no ambiente de trabalho. In: ENCONTRO ANUAL DA ASSOCIAÇÃO NACIONAL DE PÓS-GRADUAÇÃO E PESQUISA EM ADMINISTRAÇÃO, Rio de Janeiro, XXXI, Anais... Rio de Janeiro: ANPAD, 2007.

IRIGARAY, H. A. R.; FREITAS, M. E. Sexualidade e organizações: estudo sobre lésbicas no ambiente de trabalho. Organizações \& Sociedade, Salvador, v. 18, n. 59, p. 625-641, out./dez. 2011.

IRIGARAY. H. A.; SARAIVA, L. A. S.; CARRIERI, A. P. Humor e discriminação por orientação sexual no trabalho. Revista de Administração Contemporânea, Curitiba, v. 14, n. 5, p. 890-906. set./out. 2010.

MASCARENHAS, A. O. Gestão da diversidade. In: MASCARENHAS, A. O. (Org.). Gestão estratégica de pessoas: evolução, teoria e crítica. São Paulo: Cengage Learning, 2008. p. 259270.

MEIHY, J. C. S. B. Manual de história oral. São Paulo: Loyola, 1996. 291 p.

NUNAN, A. Homossexualidade: do preconceito aos padrões de consumo. Rio de Janeiro: Caravansarai, 2003. 360 p.

PEREIRA, S. J. N. Da invenção da homossexualidade ao discurso das posses: uma análise interpretativa da identidade homossexual. $191 \mathrm{f}$. Tese (Doutorado em Administração) - Escola Brasileira de Administração Pública e de Empresas, Fundação Getúlio Vargas, Rio de Janeiro, 2009.

PICAZIO, C. Sexo secreto: temas polêmicos da sexualidade. São Paulo: Summus, 1998. 136 p.

PRADO, M. A. M.; MACHADO, F. V. Preconceito contra homossexualidades: a hierarquia da invisibilidade. São Paulo: Cortez, 2008. 144 p.

RAGINS, B. R.; CORNWELL, J. M. Pink triangles: antecedents and consequences of perceived discrimination against gay and lesbian employees. Journal of Applied Psychology, Washington, v. 86, n. 6, p. 1244-1261, Dec. 2001.

SANTOS, H. M. R. Um desvio na corrente que(er)stionando as margens: percursos escolares e culturas juvenis de rapazes não heterossexuais. 2013. 145 f. Dissertação (Mestrado em Ciências da Educação) - Faculdade de Psicologia e Ciências da Educação, Universidade do Porto, Porto, 2013.

SARAIVA, L. A. S.; IRIGARAY, H. A. R. Políticas de diversidade nas organizações: uma questão de discurso? Revista de Administração de Empresas, São Paulo, v. 49, n. 3, p. 337-348. jul./set. 2009

SIQUEIRA, M. V. S.; ZAULI-FELLOWS, A. Diversidade e identidade gay nas organizações. Gestão.org, Recife, v. 4, n. 3, p. 70-81. nov./dez. 2006.

SIQUEIRA, M. V. S.; SARAIVA, L. A. S.; CARRIERI, A. P.; LIMA, H. K. B.; ANDRADE, A. J. A. 
Homofobia e violência moral no trabalho no distrito federal. Organizações e Sociedade, Salvador, v. 16, n. 50, p. 447-461. jul./set. 2009.

TROIDEN, R. R. Homosexual identity development. Journal of Adolescent Health Care, Oxford, v. 9 n. 2, p. 105-113, Mar. 1988. 